\title{
EL GUADIANA Y LA REAL DEHESA DE ZACATENA A FINALES DEL ANTIGUO RÉGIMEN. PROYECTOS DE DESECACIÓN, CAMBIOS AMBIENTALES Y CONFLICTIVIDAD INSTITUCIONAL
}

\author{
Francisco J. Moreno Díaz del Campo \\ Universidad de Castilla-La Mancha \\ franciscoj.moreno@uclm.es \\ ORCID iD: https://orcid.org/0000-0001-7929-5080
}

Recibido: 12/11/2020; Aceptado: 16/07/2021; Publicado: 10/12/2021

Cómo citar este artículo/citation: Moreno Díaz del Campo, Francisco J. (2021). El Guadiana y la Real Dehesa de Zacatena a finales del Antiguo Régimen. Proyectos de desecación, cambios ambientales y conflictividad institucional. Estudios Geográficos, 82 (291), e072. https://doi.org/10.3989/estgeogr.202183.083

RESUMEN: A mediados del siglo XVIII, la Corona intervino en el cauce alto del río Guadiana para desecar su ribera y aumentar las tierras de cultivo y pasto. La obra, reclamada por las elites locales, se ha puesto como reflejo del antagonismo entre molineros y ganaderos en un contexto dominado por el deseo regio de aumentar los ingresos estatales. No obstante, el proyecto no solo pretendía disminuir la influencia del río, sino reordenar los recursos naturales de la comarca. Este trabajo analiza el resultado de aquella operación basándose en el deslinde ejecutado tras la finalización de la obra. Para ello se traza una panorámica del estado en que quedó la vega tras el drenaje del río, se analiza el impacto socioeconómico de aquella intervención y se contextualizan los cambios institucionales y jurisdiccionales que se derivaron de ella. También se han estudiado las transformaciones paisajísticas que tuvieron lugar y los problemas que las autoridades encontraron a la hora de asegurar la permanencia del proyecto. Para ello se ha hecho uso de documentación archivística, especialmente judicial. La principal conclusión que se ha extraído es que las condiciones naturales y ambientales resultantes de aquella intervención fueron endebles y transitorias, y no solo por la vitalidad del medio fluvial; también a causa de los intereses contrapuestos que protagonizaron las gentes que vivieron del río y en el río.

PALABRAS CLAVE: Geografía histórica; paisaje; agua; molinos harineros; Castilla la Nueva; siglo XVIII

The Guadiana River and the Real Dehesa de Zacatena at the end of the Ancient Regime. Drainage projects, environmental changes and institutional disputes

ABSTRACT: In the mid-18th century, the Spanish Crown took action in the Guadiana riverbed to drain its banks and increase the land for cultivation and grazing. The project, which was demanded by the local elites, has been presented as a reflection of the antagonism between millers and cattle breeders in a context dominated by the government intention to increase state income. However, the plan was not intended to diminish the river influence, but also to reorder the natural resources of the region. This paper analyses the result of that public operation on the basis of the boundary carried out after the work was completed. To this end, the river situation after the drainage is studied. In addition, the socio-economic impact of that works has been analysed, as well as the institutional and jurisdictional changes that came of it. Finally, the landscape transformations and the problems which were encountered by the authorities in ensuring the permanence of the project have been also studied. For this purpose, historic records have been used, especially judicial ones. The result has been the confirmation that the landscape conditions that result of the project could not be durable, not only because of the vitality of the river environment, but of the diverging interests of the people who lived off of the river.

KEYWORDS: Historical Geography; landscape; water; water mills; New Castile; 18th Century 


\section{INTRODUCCIÓN}

A finales del siglo XVIII, los freiles de Santa María del Monte (Urda, Toledo) se vieron inmersos en un proceso judicial contra la Corona. El "sacro y militar convento", en el que se formaban los religiosos de la todopoderosa orden militar de San Juan, era propietario del molino harinero de Zuacorta, emplazado a orillas del río Guadiana, en el término de Villarrubia de los Ojos (Ciudad Real). En la demanda, se les acusaba de elevar el nivel de su azud, de aumentar artificialmente el nivel de la balsa y de contravenir las normas establecidas por el juez privativo de los "desaguados del Guadiana". Este último concepto es utilizado para referirse al resultado de las actuaciones que tuvieron lugar entre los años 1750 y 1756 y que afectaron al tramo del río comprendido entre su nacimiento -en los Ojos - y el término municipal de Ciudad Real (figura 1). Por su significación y por las consecuencias que tuvo para aquella comarca, puede decirse que aquella obra fue una de las más destacadas de cuantas se acometieron en la región manchega durante el siglo ilustrado (Arroyo, 1993; Celis, 2013; Celis et al., 2019). Su carácter público, y el hecho de estar auspiciada por la monarquía española, convierten a la "Real Obra del Guadiana" en un temprano ejemplo del empeño que los primeros borbones mostraron a la hora de promover un cambio en la estrategia de explotación del territorio (Gil, 1992; López, 2004). Prueba de esto último son los trabajos que, en el reinado de Felipe $V$, condujeron a la finalización de la Real Acequia del Jarama (Arroyo, 2002); también aquellas intervenciones, que, sin salir de Castilla la Nueva, tuvieron lugar en el entorno de las lagunas de Ruidera y que dieron lugar al levantamiento del canal del Gran Prior (Marín, 2007; Marín et al., 2008; Fidalgo et al., 2013; Moleón, 1998, pp. 67-77). Igualmente importantes, aunque no $\tan$ ambiciosos $-y$, sin duda, menos conocidos - fueron los proyectos que intentaron abastecer de agua potable a algunas de las localidades manchegas más necesitadas del líquido elemento (Moreno, 2009).

El tema presenta otras derivadas, cuya contextualización es necesaria para valorar adecuadamente el desarrollo del plan que llevó a la desecación parcial de la ribera del Guadiana. Entre esos aspectos cabe destacar la importancia que tuvieron los molinos harineros que jalonaron aquel tramo del río. Los inge-

FIGURA 1.

LOCALIZACIÓN DE LA CUENCA DEL RÍO BEMBÉZAR

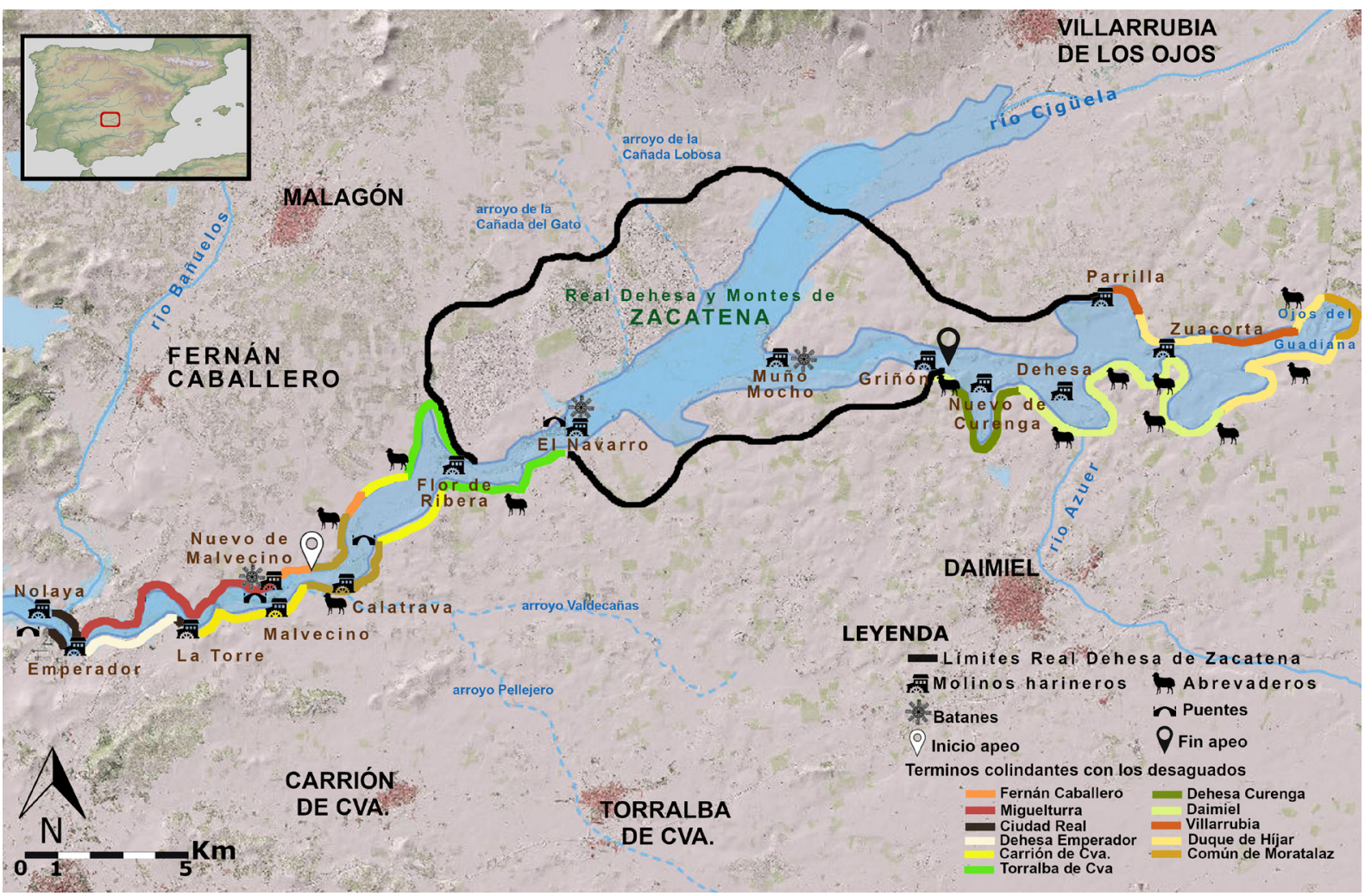

Fuente: AHN, OM, leg. 6433-3, fols. 134v-156v y 235r-320v 
nios hidráulicos del Guadiana constituyeron un hito geográfico de primer orden en la época preindustrial. Su importancia trasciende lo meramente paisajístico, ya que actuaron como motor económico de la zona; también fueron reguladores de la tupida red de relaciones socioeconómicas y político-administrativas que caracterizaron a aquel territorio durante el Antiguo Régimen (Moreno, 2014). Su ubicación y funcionamiento fueron fruto de un preciso conocimiento de las potencialidades del medio, basado en la experiencia acumulada desde la Edad Media y sostenido por una práctica administrativa y judicial que fue capaz de regular los usos económicos del río para garantizar la paz social entre usuarios, propietarios y autoridades (Santos y Moreno, 2009).

Como quiera que en el epicentro de aquella comarca se situaba la Real Dehesa de Zacatena, es preciso añadir que el tema presenta aspectos relevantes en todo lo que se refiere a la gestión de los aprovechamientos pecuarios y forestales, algo que aún tiene bastante recorrido metodológico (Fernández, 2020). No obstante, existen contribuciones muy bien fundamentadas relativas a otros ámbitos novocastellanos. En ese sentido, son relevantes tanto los trabajos que han analizado el valle de Alcudia (Corchado 1972; López-Salazar, 1983; 1987) como los que se han centrado en las dehesas maestrales de Extremadura (Sánchez, 2001; Hernández, 2002; Clemente, 2014). En ambos casos su proceso de privatización corrió paralelo al de la propia Zacatena, si bien es cierto que mantienen ciertas diferencias con respecto al espacio que nos ocupa, en especial en lo relativo al tema hídrico, allí ausente.

\section{FUENTES y METOdOLOGÍA}

La obra de desaguado del Guadiana ha sido analizada prestando atención al plan de drenaje del río. Los estudios más recientes han dado a conocer el resultado inmediato de aquella intervención, al tiempo que insisten en su trascendencia posterior como motor de la degradación ambiental sufrida por aquella comarca (Celis, 2013). Se trata de aportaciones relevantes, que alertan de un cambio de tendencia en la política de explotación del territorio seguida por las autoridades estatales hispanas durante el Setecientos. No obstante, es necesario profundizar en varios aspectos. El primero es el temporal: hace falta conocer cuáles fueron los efectos más visibles de aquella intervención y cómo se transformó el medio fluvial del Guadiana en los años inmediatamente posteriores a la finalización del proyecto. Esta última cuestión tiene mucho que ver con las consecuencias de tipo paisajístico que llevó implícita aquella actuación. También es necesario abordar cómo y en qué medida se produjo la reordenación de los recursos naturales en la comarca. Algunos estudios se han centrado en el asunto hídrico - sin duda, el más importante-, pero mirando hacia atrás en el tiempo (Celis et al., 2019). Otros enfoques han prestado atención a aspectos más particulares y han tomado como referencia cronologías más amplias (Celis et al., 2017). En todo caso, siempre se ha dado por sentado que el resultado de la obra condujo a cambios económicos y productivos, pero esas transformaciones no han sido convenientemente delimitadas e interrelacionadas. Sin dejar de lado tales aspectos, esta contribución se ocupa del impacto de los trabajos en relación con otros recursos como los agrícolas y pecuarios, especialmente en lo relativo al retroceso de los espacios comunales. Al mismo tiempo, se estudian las consecuencias de tipo institucional y jurídico. Se trata de un aspecto no contemplado hasta ahora, pero que es vital para conocer cómo y por qué comenzó a manifestarse el cambio de paradigma que aconteció a finales del Antiguo Régimen en las relaciones sociales y económicas de la comarca.

Para analizar todas estas cuestiones, se ha examinado documentación histórica procedente de diversos fondos archivísticos. Entre los materiales analizados se encuentran los expedientes administrativos relativos al drenaje del río. Algunos son conocidos, pero de manera parcial. Se encuentran en los autos judiciales incoados con posterioridad a la propia obra y son el resultado de las desavenencias a que dieron lugar el proyecto y su posterior gestión. Junto a ello, deben considerarse los fondos de tipo judicial y administrativo conservados en la sección Órdenes Militares del Archivo Histórico Nacional de Madrid, así como la documentación municipal y notarial relativa a la comarca estudiada. En su inmensa mayoría son expedientes del siglo XVIII, pero también se han analizado papeles fechados en un arco cronológico que se retrotrae hasta mediados del XVI.

El objetivo perseguido ha sido contextualizar la obra de desaguado en un marco cronológico que no toma como referente la finalización del proyecto mismo, sino que analiza sus consecuencias inmediatas. Gracias a ello ha podido ahondarse en las razones socioeconómicas, políticas e institucionales que explicaron su necesidad, pero también su fracaso. Igualmente se ha prestado atención al aspecto paisajístico mediante la elaboración de la figura 1 , que sistematiza lo fundamental de todos los cambios analizados en este trabajo. 


\section{RESULTADOS Y DISCUSIÓN}

La administración de los desaguados implicaba desarrollar una política integral de gestión del territorio en la comarca del alto Guadiana. El objetivo principal era aumentar la capacidad productiva de las tierras ribereñas y beneficiar a los distintos agentes económicos presentes en la zona, especialmente en la vertien- te norte de la Real Dehesa de Zacatena, que también estaba regada por el río Cigüela. Al mismo tiempo, se perseguía facilitar una retroalimentación de la inversión realizada por la Corona. Las vías elegidas para ello fueron la venta y arrendamiento de las tierras desecadas y el cobro de exacciones fiscales como consecuencia de aquella puesta en explotación.

TABLA 1

DESLINDE DE LOS DESAGUADOS DEL GUADIANA

\begin{tabular}{|c|c|c|c|c|c|c|}
\hline \multirow{4}{*}{ TÉRMINO O JURISDICCIÓN (1) } & \multicolumn{6}{|c|}{ RESULTADO DEL DESLINDE } \\
\hline & \multicolumn{3}{|c|}{ número de hitos } & \multicolumn{3}{|c|}{ longitud (en km) } \\
\hline & \multicolumn{2}{|c|}{ orilla } & \multirow{2}{*}{ total } & \multicolumn{2}{|c|}{ orilla } & \multirow{2}{*}{ total } \\
\hline & norte & sur & & norte & sur & \\
\hline \multirow{2}{*}{ Fernán Caballero } & 16 & & \multirow{2}{*}{21} & $1,7^{(2)}$ & & \multirow{2}{*}{2,6} \\
\hline & 5 & & & $0,9^{(3)}$ & & \\
\hline Miguelturra & 23 & & 23 & 6,2 & & 6,2 \\
\hline \multirow{2}{*}{ Ciudad Real } & 4 & & \multirow{2}{*}{18} & 0,7 & & \multirow{2}{*}{2,1} \\
\hline & & 14 & & & $1,4^{(4)}$ & \\
\hline $\begin{array}{l}\text { Dehesa del Emperador } \\
\text { (Colegio de Doncellas Nobles de Toledo) }\end{array}$ & & 10 & 10 & & 1,1 & 1,1 \\
\hline \multirow{3}{*}{ Carrión de Calatrava } & & 31 & \multirow{3}{*}{75} & & $5,1^{(5)}$ & \multirow{3}{*}{11,6} \\
\hline & & 14 & & & $2^{(6)}$ & \\
\hline & 30 & & & & 4,5 & \\
\hline \multirow{2}{*}{$\begin{array}{l}\text { Dehesa de Calatrava (encomienda de } \\
\text { Carrión) }\end{array}$} & & 39 & \multirow{2}{*}{48} & & 4,7 & \multirow{2}{*}{7,4} \\
\hline & 9 & & & 2,7 & & \\
\hline \multirow{2}{*}{ Torralba de Calatrava } & & 10 & \multirow{2}{*}{33} & & 1,8 & \multirow{2}{*}{5,8} \\
\hline & 23 & & & 4 & & \\
\hline \multirow{3}{*}{ Daimiel } & & 19 & \multirow{3}{*}{88} & & 3,3 & \multirow{3}{*}{15,4} \\
\hline & & 65 & & & $11,3^{(7)}$ & \\
\hline & & 4 & & & $0,78^{(8)}$ & \\
\hline Dehesa de Curenga (encomienda de Daimiel) & & 15 & 15 & & 7,2 & 7,2 \\
\hline \multirow{2}{*}{$\begin{array}{l}\text { Término de Moratalaz } \\
\text { (común Daimiel y Villarrubia) }\end{array}$} & 4 & & \multirow{2}{*}{7} & 0,6 & & \multirow{2}{*}{1,2} \\
\hline & & 3 & & & 0,6 & \\
\hline \multirow{2}{*}{$\begin{array}{l}\text { Dehesilla de los Ojos } \\
\text { (Duque de Híjar) }\end{array}$} & 15 & & & 2,8 & & \\
\hline & & 29 & 44 & & 7,2 & 10 \\
\hline Dehesilla de Zuacorta (Duque de Híjar) & 23 & & 23 & 3,6 & & 3,6 \\
\hline \multirow{2}{*}{ Villarrubia } & 10 & & \multirow{2}{*}{35} & $1,6^{(9)}$ & & \\
\hline & 25 & & & $4^{(10)}$ & & 5,6 \\
\hline
\end{tabular}

(1) A pesar de comenzar en el centro de la ribera, se presentan los datos según el orden seguido en el apeo. Vid. figura 1

(2) Aguas abajo de la Dehesa de Calatrava. Tramo dividido en dos deslindes 5.11.1753 y 20.5.1754. No indica distancia entre mojones 8-9 del apeo de 1753.

(3) Aguas arriba de la Dehesa de Calatrava.

(4) Incluye 260 pasos $(0,18 \mathrm{~km})$ de la "yntermedia" situada entre Dehesa del Emperador y Carrión.

(5) Aguas abajo de la Dehesa de Calatrava. No indica distancia entre mojones 10-11 y 23-24.

(6) Aguas arriba de la Dehesa de Calatrava, hasta el molino de Flor de Ribera (Torralba de Cva.).

(7) Dehesa del Concejo. No indica distancia entre mojones 64 y 65.

(8) Pedazo del Ojo de la Peñuela, aguas abajo de la Dehesa de Curenga (encomienda de Daimiel).

(9) Aguas abajo de la Dehesilla de Zuacorta.

(10) Aguas arriba de la Dehesilla de Zuacorta.

Fuente: AHN, OM, leg. 6433-3, fols. $134 v-156 v$ y $235 r-320 v$. 


\subsection{El desaguado del Guadiana: su delimitación}

El alcance de los trabajos de drenaje del río puede evaluarse gracias al amojonamiento que se ejecutó de manera paralela a la propia obra (tabla 1). Para llevar a cabo aquel deslinde, los delegados regios desplegaron una mínima infraestructura logística de la que formaron parte peones de albañil, carreteros, agrimensores y un escribano. Las tareas fueron supervisadas por los representantes de las jurisdicciones a las que afectó el amojonamiento, quienes asistieron a los trabajos con el derecho a "voto de protesta" en el caso de que consideraran que el señalamiento lesionaba los intereses de sus representados como linderos del río. Entre estos últimos se contaban los concejos - que hablaban por sí y por sus vecinos- y las encomiendas de la orden de Calatrava, pero también grandes propietarios privados como el duque de Híjar, el señor de Malagón o el colegio de los jesuitas de Almagro.

El deslinde afectó a los dos tramos del río que separa la Real Dehesa de Zacatena, que fue amojonada en un proceso separado, pero paralelo. La operación tuvo lugar en sendas fases y para su formalización se recorrieron ambas orillas. En la primera (noviembre de 1753) se recorrieron los términos de Miguelturra, Carrión de Calatrava, Ciudad Real y las dehesas del Emperador y de Calatrava, además de parte de las tierras de Fernán Caballero. En la segunda etapa, que se desarrolló en el mes de mayo del año siguiente, se apearon los términos de Torralba de Calatrava, Daimiel, Villarrubia de los Ojos y las tierras del duque de Híjar, señor de esta última villa. El apeo se dio por concluido con el amojonamiento de las tierras de Fernán Caballero que habían quedado sin ahitar en la primera fase (figura 1).

En total se colocaron cuatrocientos cuarenta mojones repartidos a lo largo de casi ochenta kilómetros de ribera (tabla 2). La operación sirvió para delimitar la parte teóricamente liberada de las aguas de aquella otra que seguía estando dominada por el río. Con ello quedaba allanado el camino para la posterior privatización de las tierras drenadas y se delimitaba una suerte de "dominio público", cuyo contorno era más reducido que el que existía antes de la obra, pero también más amplio que el definido por la zanja excavada en los años setenta del siglo $\mathrm{XX}$, que marca la actual madre del río y que, al igual que en el siglo XVIII, persiguió encauzar el río y ofrecer más tierras de labor a los habitantes de la zona. El retroceso de la superficie encharcada era evidente. Sin embargo, aquella ribera, más sinuosa $-y$ larga-en su orilla sur, no tenía nada que ver con la dramática visión que ofrece hoy el Guadiana y todo indica que su aspecto era mucho
TABLA 2

LONGITUD DE LA RIBERA GUADIANA. COMPARATIVA ACTUALIDAD/SIGLO XVIII

\begin{tabular}{|l|c|c|c|}
\hline \multirow{2}{*}{\multicolumn{1}{|c|}{ tramo }} & \multirow{2}{*}{$\begin{array}{c}\text { longitud } \\
\text { actual } \\
\text { (en km.) }\end{array}$} & \multicolumn{2}{c|}{$\begin{array}{c}\text { longitud deslinde } \\
\text { (en km.) }\end{array}$} \\
\cline { 3 - 4 } & & $\begin{array}{c}\text { orilla } \\
\text { norte }\end{array}$ & orilla sur \\
\hline Ojos del Guadiana-Griñón & 13,2 & 12,6 & 30,4 \\
\hline Flor de Ribera-Doña Olalla & 11,8 & 16,2 & 20,6 \\
\hline Total & 25 & 28,8 & 51 \\
\hline
\end{tabular}

Fuente: AHN, OM, leg. 6433-3, fols. 134v-156v y 235r-320v e Hidrografía General de Castilla-La Mancha (https://castillalamancha.maps.arcgis.com) [fecha de consulta: 23.10.2020].

más parecido al que tenía a mediados del siglo pasado, cuando las excavadoras aún no habían entrado en el cauce. De ahí los desfases entre las distancias antiguas y las actuales.

Hay dos cuestiones que impiden calibrar de manera concluyente el impacto paisajístico de la obra. Ambas tienen que ver con la ausencia de datos precisos que informen, primero, acerca de la superficie total sobre la que se actuó y, en segundo término, sobre el número de hectáreas que se desecaron en cada parte del río. Los datos más contundentes están reflejados en el informe emitido a la finalización de las obras por el contador general de las órdenes militares ${ }^{1}$. En él se concluía que se habían drenado 10920 cuerdas de tierra, o lo que es lo mismo, 7031,4 hectáreas². La medición se había realizado de manera paralela al amojonamiento de la ribera. La parte situada aguas abajo de la Real Dehesa de Zacatena se revisó en noviembre de 1753 (tabla 3). En aquel momento, el desaguado aún no había finalizado, por lo que puede decirse que los datos que se ofrecieron entonces son poco consistentes: apenas se habían desecado 166 hectáreas, muy poco ${ }^{3}$. De hecho, eran muchas las zonas que permanecían inundadas ${ }^{4}$, en parte porque el grueso de la obra, situado aguas arriba, aún no había comenzado ${ }^{5}$.

Es de suponer que la medición se completó tras el amojonamiento de la parte alta del río, pero nada se sabe aún acerca de su resultado. Únicamente, se poseen datos relativos a la propia dehesa, cuyos quintos se midieron de manera independiente en el verano de $1754^{6}$. A resultas de aquella intervención se constató que los "desaguados" de Zacatena medían 4104 cuerdas (unas 2642 ha). Como era lógico esperar, la parte más afectada era la de "entrerríos", donde se situaban casi dos terceras partes de la superficie drenada (tabla 3; figura 1). La cifra es muy significativa. Gracias a la valoración previa que se hizo con motivo del Catastro de Ensenada, se sabe que la extensión total de la dehesa 
TABLA 3

EXTENSIÓN DESAGUADA EN LA REAL DEHESA DE ZACATENA, APEOS DE 1754 Y 1762

\begin{tabular}{|c|c|c|c|c|c|c|c|c|c|}
\hline \multicolumn{5}{|c|}{ al norte del Cigüela } & \multicolumn{5}{|c|}{ al sur del Guadiana } \\
\hline \multirow{2}{*}{ quinto } & \multicolumn{2}{|c|}{1754} & \multicolumn{2}{|c|}{1762} & \multirow{2}{*}{ quinto } & \multicolumn{2}{|c|}{1754} & \multicolumn{2}{|c|}{1762} \\
\hline & cuerdas & ha & cuerdas & ha & & cuerdas & ha & cuerdas & ha \\
\hline de Casablanca & $200^{(2)}$ & 128,78 & 210 & 135,22 & Medios Quintos & 30 & 19,32 & 57 & 36,86 \\
\hline de la Cañada Lobosa & $100^{(3)}$ & 64,39 & 66 & 42,18 & de la Colmena & 22 & 14,17 & 5 & 3,22 \\
\hline de la Torre & 188 & 121,05 & 55 & 35,41 & de los Pradicos & 85 & 54,73 & 32 & 20,60 \\
\hline de la Cañada del Gato & 80 & 51,51 & 142 & 91,11 & de Calabazas & 20 & 12,88 & 52 & 33,27 \\
\hline de la Casa & 44 & 28,33 & 149 & 95,94 & de la Laguna & 10 & 6,44 & 10 & 6,44 \\
\hline de Magarzal & 36 & 23,18 & 75 & 48,29 & de los Morales & 160 & 103,02 & 80 & 51,51 \\
\hline \multirow[t]{5}{*}{ de la Muela } & $50^{(4)}$ & 32,20 & 36 & 23,18 & de doña Juana & 150 & 96,59 & 145 & 93,04 \\
\hline & & & & & de Cañada Mendoza & 36 & 23,18 & 149 & 95,94 \\
\hline & & & & & del Torvisquillo & 80 & 51,51 & 79 & 50,71 \\
\hline & & & & & de don Pedro & 55 & 35,41 & 40 & 25,92 \\
\hline & & & & & de Juan Ga a Serrano & 70 & 45,07 & 100 & 64,39 \\
\hline total & 698 & 449,44 & 696 & 447,83 & total & 718 & 462,32 & 748 & 481,91 \\
\hline \multicolumn{10}{|c|}{ «entrerríos» (Cigüela y Guadiana) } \\
\hline \multirow{2}{*}{ quinto } & \multicolumn{2}{|c|}{1754} & \multicolumn{2}{|c|}{1762} & \multirow{2}{*}{ quinto } & \multicolumn{2}{|c|}{1754} & \multicolumn{2}{|c|}{1762} \\
\hline & cuerdas & ha & cuerdas & ha & & cuerdas & ha & cuerdas & ha \\
\hline de la Isla & 180 & 115,90 & 149 & 95,94 & del Chaparrillo & 95 & 61,17 & 65 & 41,96 \\
\hline de la Puerta & $1700^{(5)}$ & 1094,63 & 817 & 525,74 & de Griñón & 38 & 24,47 & 54 & 34,77 \\
\hline de los Bernales & $300^{(6)}$ & 193,17 & 226 & 145,52 & de las Mozas & $175^{(8)}$ & 112,68 & 140 & 89,82 \\
\hline de Algeciras & $200^{(7)}$ & 128,78 & 100 & 64,39 & & & & & \\
\hline total & 2380 & 1532,48 & 1292 & 831,60 & total & 308 & 198,32 & 259 & 166,56 \\
\hline & & & & & total general & 4104 & 2642,56 & 2994 & 1927,89 \\
\hline
\end{tabular}

(1) la cifra indicada corresponde a la extensión "toda desaguada". Cuerdas de 96 varas en cuadro. 1 cuerda=0,6439 ha

(2) "hay mucha parte de dichas cuerdas todavía con agua

(3) "con parte de tierra aguada"

(4) desaguada la mitad

(5) quedan por desaguar doscientas cuerdas

(6) quedan aguadas "la tercera parte de ellas"

(7) por desecar "treinta cuerdas que se allan (sic) aguadas en diferentes charcos"

(8) "la mitad de ellas se allan (sic) aguadas, aunque con poca agua"

Fuente: AHN, OM, leg. 6433-3, fols. 355r-363r, 15.7.1754 y AHN, Consejos 51.188-1. 26.01.1762.

era de 15484 cuerdas (9970 ha), de las cuales 10434 eran aprovechadas por el ganado y 5050 permanecían inundadas ${ }^{7}$. De ser correctas ambas estimaciones (la del Catastro y la del apeo de 1754), las 4104 que se habían desecado dejaban en 946 las cubiertas por el agua. Se había reducido la superficie encharcada a una quinta parte de lo que ocupaba antes de su intervención. Aparentemente, el plan había resultado eficaz, y no solo en Zacatena puesto que el $60 \%$ de las tierras drenadas se encontraba aguas arriba y abajo de la dehesa.

Con todo, fueron resultados parciales y transitorios. Los resultados de un nuevo deslinde hecho en 1762 confirmaron que el trabajo realizado hasta entonces tenía sus puntos débiles. Por aquel entonces, se estaba preparando la venta de Zacatena y los apeadores constataron que el drenaje del río había avanzado en algunos puntos. No obstante, el nivel de encharcamiento seguía siendo elevado y había quintos de la dehesa en los que la lámina de agua no solo no había retrocedido, sino que ocupaba más espacio que en 1754 (tabla 3).

\subsection{Cambios socioeconómicos e institucionales}

\subsubsection{Parcelación jurisdiccional y disolución de res- ponsabilidades}

La gestión de aquel "nuevo" Guadiana dio un cambio radical cuando la Corona unió los destinos del río a los de la dehesa de Zacatena, de tal manera que la 
obra de drenaje se convirtió en el paso previo para la privatización del coto real. La de Zacatena era una de las dehesas más valoradas por la Orden de Calatrava. En la Edad Media había sido propiedad de la Mesa Maestral, pero desde el siglo XVI fue gestionada por los monarcas en tanto que administradores perpetuos de los maestrazgos. Desde un punto de vista jurisdiccional, su gobierno recayó desde el siglo XV en el guarda mayor, quien regía el día a día de la dehesa de acuerdo con unas ordenanzas (Fernández, 2020). Si bien estas últimas no experimentaron modificaciones sustanciales desde finales del siglo XVI, la figura del guarda sí fue objeto de cambios. El proceso inflacionista de honores en que se vio inmersa la Monarquía Hispánica en el siglo XVII hizo que la guardería mayor de Zacatena se convirtiera en una prebenda, cuyos titulares rara vez pisaron la comarca. Debido a ello, el control efectivo de la dehesa recayó en manos de tenientes de guarda, personajes más vinculados al territorio que, generalmente, accedieron al desempeño de esa labor tras el desembolso de cantidades de dinero que, en ocasiones, fueron bastante onerosas. Fue a ellos a quienes correspondió la tarea de vigilar el correcto aprovechamiento de los recursos naturales que ofrecía la dehesa. Para el resto de asuntos jurisdiccionales, los demás territorios del alto Guadiana estuvieron sujetos a las distintas instancias presentes en la zona, de entre las cuales sobresalió la gobernación del Campo de Calatrava, con sede en Almagro, dependiente del Consejo de las Órdenes Militares.

La unidad que implicaba el control ejercido por la orden sufrió un deterioro progresivo en los años que siguieron a la Real Obra. La primera manifestación de aquella quiebra jurisdiccional fue el juez de los desaguados del Guadiana, figura que, al ser de nueva creación, era totalmente ajena al entramado institucional previo. Es mucho lo que queda por saber acerca de él, pero lo cierto es que, desde el inicio de aquella intervención, este personaje ocupó un lugar central en el nuevo escenario definido por los trabajos de drenaje del río. En un primer momento, su misión consistió en controlar el desarrollo de las obras. Más tarde, llegarían el deslinde, la liquidación económica de la operación y la puesta en explotación de las tierras drenadas. Es muy posible que, entre sus funciones, también recayera la venta de las parcelas resultantes de la desecación, pero nada se sabe por ahora acerca de ese aspecto. Lo que sí se conoce es que, en el intervalo de tiempo comprendido entre el apeo y esa privatización, fue él quien administró directamente esas parcelas y quien dio cuenta del rendimiento económico que generaban ${ }^{8}$. También se sabe que, en lo sucesivo, debía actuar como juez con plenas competencias en todo lo relacionado con la gestión de la ribera del Guadiana.

Aunque entre una operación y otra mediaron casi diez años, el drenaje y deslinde del Guadiana no puede entenderse si no se tiene como referencia la posterior privatización de la dehesa de Zacatena. Buena muestra de que esa operación ya estaba definida en el momento en el que se drenó el Guadiana, es el nombramiento de un "juez privativo" para su enajenación. El primer titular de ese puesto fue Gabriel de Olmeda y Aguilar, I Marqués de los Llanos de Alguazas ${ }^{9}$, quien delegó el amojonamiento del coto en un tal Juan Bautista Chicola, abogado de los Reales Consejos, de quien se sabe que llegó a ser alcalde mayor de Castellón de la Plana (Corona, 1981, pp. 61 y ss.). Es a este personaje a quien se localiza formalizando las diligencias previas para el deslinde de la dehesa en junio de 1753 , por lo que, incluso, podría pensarse que su labor posterior también pudo servir para evaluar el alcance de la obra de desaguado, ya que, como se ha visto, el deslinde aquí analizado no afectó a la dehesa ${ }^{10}$.

Sea como fuere, fue un proceso que no concluyó hasta 1763. A juzgar por las escasas referencias que aún tenemos de él, sí se sabe que no estuvo exento de problemas, tal y como se constata a través de las divergencias que aún provocaba el apeo de la dehesa en octubre de $1762^{11}$, muy poco antes de su venta definitiva. En la raíz de aquellos problemas estaba la progresiva - pero imparable- fragmentación jurisdiccional que se produjo a partir del momento en el que la Corona decidió avanzar hacia la privatización del Guadiana y de su entorno. Como es fácil deducir, los actores implicados en aquel proceso no dudaron en aprovechar en beneficio propio aquella situación, algo que tuvo sus consecuencias.

\subsubsection{Los derechos de paso y pasto y la regulación de los espacios comunales}

Más allá de cuantificar el alcance de la obra de drenaje, el amojonamiento contribuyó a dar respuesta a algunos de los problemas seculares que habían jalonado el día a día del río. La ordenación de todos esos aspectos era vital para concretar la reestructuración económica de la comarca.

El asunto de más fácil resolución era el que se refería a los derechos de paso sobre el río. La cuestión no era baladí. Dados la anchura y el carácter casi permanente del Guadiana, la opción de vadear el río no siempre fue fácil. Se trataba de una operación com- 
pleja, especialmente para los ganados y personas que transitaban a pie. Caballerías y carruajes tuvieron menos problemas, si bien es cierto que el riesgo que corrían las mercancías era alto, especialmente en invierno. La solución a esos inconvenientes estuvo en los molinos harineros situados en la orilla del río. Su disposición arquitectónica y sus caracteres técnicos facilitaron un uso multifuncional de los mismos (Hervás, 2011, pp. 11-12), de tal manera que no solo operaron como molinos propiamente dichos, sino también como pesquerías $y$, sobre todo, adaptando la coronación de sus azudes como base para puentes (Moreno, 2014, pp. 181-182). En aquellos que eran de la Orden de Calatrava no hubo mayor problema, ya que la Corona favoreció su uso. En cambio, los propietarios privados siempre intentaron aprovechar esa posición estratégica en beneficio propio. En un claro intento de preservar sus derechos, las autoridades municipales no dudaron en recurrir a la justicia. No obstante, y para evitar posibles inconvenientes, los concejos también se aprestaron a mantener en un buen estado de conservación aquellos pasos que dependían directamente de ellos. Tal fue el caso de "la puente vieja" de Daimiel" — situado sobre el río Azuer-, del de Torralba o del que había junto al molino de Malvecino, en Carrión ${ }^{12}$. Finalmente, también ayudó a regular ese uso, la resolución de conflictos que habían permanecido enquistados durante largo tiempo como el que afectó al molino Flor de Ribera, cuyos propietarios - el colegio de los jesuitas de Almagro- siempre defendieron un uso privativo del mismo ${ }^{13}$.

La principal novedad que introdujo la obra de desaguado fue la reparación y ampliación de las pasarelas situadas en los propios molinos. Al menos seis fueron reforzadas: doña Olalla, el Emperador, Malvecino, Muño Mocho, Griñón y El Nuevo de Curenga (figura 1). En este último, incluso, se construyeron dos pasos nuevos: uno "angostico", que era utilizado para el tránsito de personas, y otro para carruajes, situado sobre los tajamares del edificio principal. El molino de Muño Mocho también dispuso de dos: uno era del molino mismo, tenía cuatro ojos y fue totalmente reformado; el otro estaba en la parte norte de su azuda y pertenecía a un batán anejo, cuya propiedad sufragó la reforma. A ellos cabe añadir el puente construido junto al desaparecido molino de El Navarro ${ }^{14}$, paso que había que preservar, ya que conectaba con la casa de los guardas de Zacatena y, sobre todo, con Malagón, a cuyos pies estaba el camino real que unía Córdoba y Sevilla con Toledo (Diago y Ladero, 2009; Sánchez, 2006).
Gran parte del tráfico que soportaban aquellos puentes se debía a la necesidad de dar pasto y abrevadero a los rebaños de las villas situadas al sur del Guadiana. De hecho, muchas de las quejas de los propietarios de los molinos se dirigieron expresamente contra la actividad pecuaria. Desde finales del siglo XVII y, al menos, hasta 1745 , el propio molino de Flor de Ribera fue escenario de una sucesión de pleitos en los que se trató de dirimir si los vecinos de Torralba podían utilizar aquel paso para conducir sus rebaños al ejido de Campomojado, situado al otro lado del Guadiana ${ }^{15}$.

Los problemas con los propietarios de ganado no solo lo fueron a cuenta de los lugares de paso. Algunos estuvieron relacionados con los pastizales, que fueron violentados de manera recurrente por los labradores linderos. En otros casos, ocurrió a la inversa, de tal manera que no es extraño ver a unos y a otros en los tribunales, bien fuera para resarcirse de los daños provocados por los ganados bien para evitar que los agricultores redujeran los lugares de herbajeo ${ }^{16}$.

En el caso que se analiza aquí, la disputa también se extendía a los propietarios de los molinos, cuyas balsas llegaron a inundar algunos sembrados. El constante goteo de procesos judiciales a lo largo de toda la Edad Moderna da cuenta de la importancia que ganaderos y agricultores concedieron a estos aprovechamientos, si bien es cierto que su resolución fue relativamente fácil, pues "bastaba con aplicar la ley" (López-Salazar, 1987, p. 67). Para ello solo era necesario respetar los prados comunales. La existencia de estos espacios - y de las cañadas que daban acceso a ellos - se amparaba en la tradición, estaba regulada por la legislación y reconocida por sentencias a favor de los vecinos de las villas limítrofes con el río. Nuevamente, el caso de Torralba es un buen ejemplo de ello. Con motivo de la construcción de la prensa de aceite que los jesuitas pretendían erigir en su molino en 1717, el concejo recordó que "de tiempo inmemorial" (al menos desde el siglo XVI)

tenían asignada para pastos y abrevaderos de los ganados conzejiles y cavañiles, con prohibición de fábricas y labores, una vereda, que dizen de la Retuerta del Molinillo, la qual corre debajo de sus límites y mojones desde la fuente de Zacatena y Saladillo, hasta la dehesa de Calatrava la Vieja, por la ribera de dicho río, y en ella tres abrevaderos; el primero que llaman de dicha fuente; el segundo de la Retuerta; y el tercero Fuente de los $\operatorname{Cotos}^{17}$.

El juez de comisión de los desaguados fijo allí uno de los abrevaderos que fueron contemplados en el apeo. En este caso concreto, lo hizo amparándose en 
la tradición, pero fueron varias las ocasiones en las que su establecimiento se debió a la presión de los concejos, cuyos representantes se negaron a aceptar un deslinde sin concesiones a la propiedad comunal. Gracias a aquellas presiones, que fueron especialmente intensas en Daimiel, las villas del Guadiana dispusieron de espacios específicos para sus ganados, tanto en el tramo más cercano a los Ojos, como aguas abajo de Zacatena (figura 1). Sin embargo, lo más importante es que aquellos parajes estaban llamados a no entorpecer la libre disposición de sus terrenos por parte de los futuros propietarios que se beneficiaran de la venta de los desaguados. Bajo la apariencia de cesión a la comunidad, afloraba un nuevo guiño a los intereses privados.

\subsubsection{Los molinos hidráulicos: un ¿cuestionado? ele- mento de referencia.}

En el memorial que inspiró la obra de desaguado, se dejó caer la idea de que el encharcamiento de la ribera se debía a la altura excesiva de la presa del molino de El Navarro, que retenía las aguas de los tablares originados por la confluencia del Cigüela y del Guadiana (Celis et al., 2019, p. 86). Al fijar su mirada en aquel lugar, los peticionarios intentaban marcar el camino a la Corona, pero sin advertir -o sin querer hacerloque el mismo problema afectaba al resto de molinos (figura 1). Se trataba de una situación endémica, que estaba motivada por el deseo de aumentar la rentabilidad de cada ingenio: a más agua almacenada, más tiempo de molienda, más presión acumulada y más velocidad de las ruedas; en definitiva, más beneficio. La gestión de ese aprovechamiento había permanecido casi inalterada durante siglos, pero comenzó a trastocarse a finales del XVII, cuando algunos de los molinos harineros fueron objeto de obras de ampliación y reforma. Las intervenciones más importantes se produjeron en los que caían bajo la órbita de la orden de Calatrava, especialmente en los gestionados por la Mesa Maestral. Muño Mocho fue remozado entre 1717 y $1719^{18}$. Por las mismas fechas, los albañiles también entraron en Malvecino: la lluvia caída durante el invierno de 1716-1717 había provocado daños en sus cimientos y era urgente asegurar la viabilidad del ingenio ${ }^{19}$. También se intervino en La Dehesa ${ }^{20}$ y en El Nuevo de Curenga ${ }^{21}$, propiedad de la encomienda daimieleña. Más tarde sería el turno de El Navarro. En este caso, los trabajos comenzaron en $1726^{22}$, pero se prolongaron durante años dando lugar a una maraña de procesos judiciales que no culminaron, al menos, hasta $1735^{23}$. Los cambios también afectaron a los molinos de titularidad privada. Las obras más im- portantes fueron ejecutadas en el de Flor de Ribera. Fueron, incluso, más tempranas y afectaron a su pre$\mathrm{sa}^{24}$ (Moreno, 2005). En los años veinte del XVIII siguió habiendo intervenciones ${ }^{25}$.

Si tales actuaciones se debieron a un cambio de coyuntura económica, o si estuvieron motivadas por cuestiones de índole puntual, como las lluvias excesivas, es algo que cabe analizar con cierta calma. De lo que no cabe duda es de que, en aquellos años, hubo cierta efervescencia constructora y de que todo ello derivó en un aumento de los litigios, cuya tipología - observada desde el siglo XVI- coincide con la establecida por Santos y Moreno (2009) ${ }^{26}$. El estudio de aquellos fallos pone en evidencia la inexistencia de una doctrina clara por parte de la Monarquía, dado que unas veces se mostró partidaria de beneficiar a los molinos que retenían agua y en otras se posicionó al lado de los que la reclamaban. Su tibieza había resultado apropiada hasta entonces porque, sentencia a sentencia, había logrado que el sistema funcionase razonablemente bien, incluso reportándole beneficios.

Por tanto, el problema no era nuevo y la pericia con la que actuó el ingeniero responsable del proyecto no solo se basaba en su erudición técnica, sino en la jurisprudencia y en el conocimiento que los vecinos de la zona tenían de su entorno más inmediato. La solución ideada consistió en derruir el ya mencionado molino de El Navarro y en intervenir directamente en las presas de los demás, rebajando sus niveles y favoreciendo que la corriente discurriera por la madre del río (Celis, 2013, p. 281). Se trataba de una estrategia que podía ser contraproducente para los molinos porque mermaba la fuerza al agua. No obstante, parece que la idea funcionó, al menos parcialmente. El resultado de la obra rebajó el encharcamiento, pero mantuvo el agua corriente. En un contexto en el que el Cigüela aportaba sus aguas invernales y en el que las surgencias dotaban de vitalidad al Guadiana, el plan era viable. Las declaraciones tomadas tras la finalización de la obra coinciden en señalar el "aumento de renta y venta" de todos los molinos, dado que trabajaban a mayor velocidad y durante más tiempo, incluso en verano ${ }^{27}$

Sin embargo, hubo matices. Los más beneficiados fueron los situados aguas abajo de la confluencia de ambos ríos, que resultaron favorecidos por la llegada de un caudal más amplio. Prueba de ello es que se construyó un nuevo ingenio en Malvecino ${ }^{28}$. Algunos declarantes, incluso, apuntaron la posibilidad de que el de Flor de Ribera pudiera trabajar con una piedra más ${ }^{29}$. También hubo perjudicados: la que más, la 
mesa maestral de la orden de Calatrava (o sea, la Real Hacienda), que vio reducido el beneficio que obtenía de Muño Mocho, su molino más rentable, al menos hasta 1754. Tras las obras, los testigos constataron su pérdida de valor ${ }^{30}$, "a causa de que entonces [antes del rebaje] andaban las piedras con más violencia" ${ }^{31}$.

La mengua de agua no fue la única causa que hizo que la Corona perdiera riqueza. Ni tan siquiera parece que aquel fuera un motivo determinante. Tuvo más importancia la reestructuración de la propiedad a que dio lugar el propio proyecto de desecación (figura 2). Como consecuencia de este, en la primavera de 1754 la Corona tomó posesión de los molinos "inobedientes", aquellos en los que ni se habían ejecutado obras ni existía constancia de que sus propietarios estuvieran dispuestos a hacerlo. Esa resistencia abrió el camino a una suerte de desamortización porque, en realidad, aquellos ingenios eran los que caían bajo la órbita de la propia orden: los tres que pertenecían a la encomienda de Daimiel (La Dehesa, Nuevo de Curenga y El Navarro) y el de La Parrilla, participado por el Sacro Convento de Calatrava y que había quedado inactivo porque la obra lo había dejado fuera de la madre del río ${ }^{32}$ (figura 1 ).

En 1756, cuando se elaboró el informe que daba cuenta de la finalización de las obras, solo funcionaban nueve molinos. De cuarenta y una piedras molientes en 1751 , solo rodaban treinta y tres (un $20 \%$ menos ${ }^{33}$. La gran perjudicada era la encomienda daimieleña (Celis et al., 2019, p. 83). En los años sucesivos, solo podría resarcirse de aquellas pérdidas con la puesta en marcha de la mitad que le correspondía del molino Nuevo de Curenga, del cual se sabe que comenzó a trabajar poco después. Por el camino también se habían lesionado los intereses de algunas pequeñas fundaciones religiosas que tenían casa en la villa de Almagro y que, por motivos obvios, dispusieron de muy poco margen para hacer frente a las obras reclamadas por la Real Hacienda ${ }^{34}$. En el extremo opuesto, todos los grandes propietarios privados retuvieron sus posesiones ${ }^{35}$. El cambio dejaba expedito el camino para medidas de mayor calado: aunque algunos de los molinos intervenidos por la Corona volvieron a ser gestionados por la orden, el horizonte para su privatización parecía definitivamente abierto, algo que terminaría por ocurrir de la mano de los procesos desamortizadores del siglo XIX. Entretanto, la Corona había reordenado sus intereses en la zona. Primero, reduciendo su posición como propietaria. Más tarde, convirtiéndose en un agente rentista, papel que consolidaría con el arrendamiento y posterior
FIGURA 2

ESTRUCTURA DE LA PROPIEDAD DE LOS MOLINOS HARINEROS DEL GUADIANA EN LA EDAD MODERNA ${ }^{(1)}$

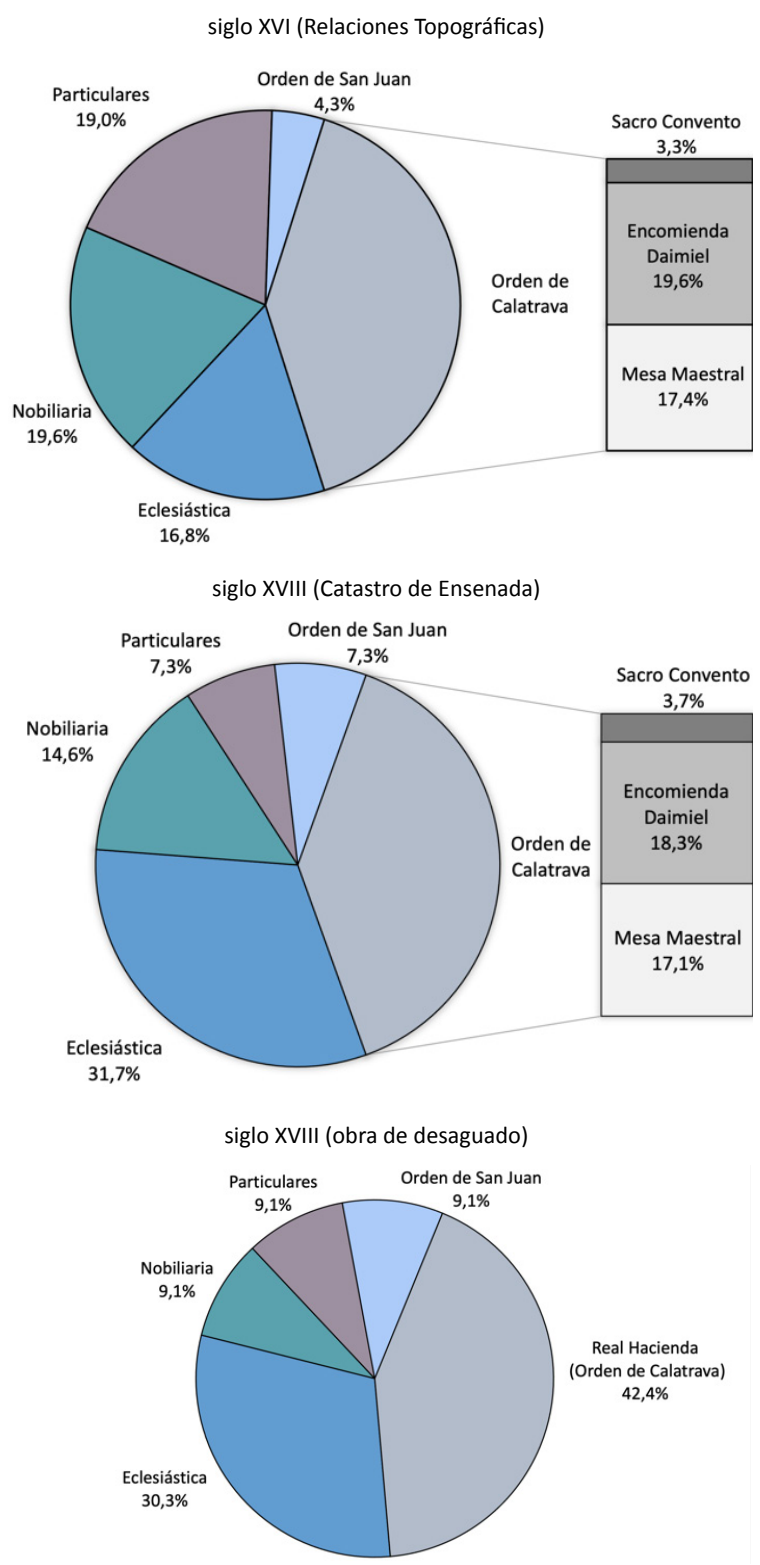

Fuente: Para el siglo XVI, Campos, 2009; para 1750-1753 (Catastro de Ensenada), Archivo General de Simancas, Dirección General de Rentas (AGS, DGR), 1 a remesa, legs. $468,469,470$ y 472 ; para siglo XVIII (obra de desaguado), AHN, OM, leg. 6433-3, fols. 409r-415v.

venta de los desaguados y de Zacatena, en un proceso muy similar al que, ya entonces, afectaba a las dehesas maestrales de Extremadura (Hernández, 2002).

La Corona advirtió a tiempo que aquella pérdida de capacidad molturadora podía ser absorbida por las piedras emplazadas en otros cauces vecinos (Moreno, 
2015 y 2017). Esa derivación de recursos - que ya era un hecho a mediados de siglo- eximía a los molinos del Guadiana de hacer frente a la demanda procedente de otras comarcas; los convertía en un instrumento local y reducía su influencia en un contexto de crecimiento económico ya de por sí limitado (López-Salazar, 1976, pp. 287-288).

En aquel escenario, los intereses de molineros y ganaderos solo convergieron durante unos años. Cuando la economía se debilitó y los primeros quisieron obtener más beneficio, las transformaciones que acaban de exponerse hicieron el resto: con una influencia económica limitada y un menor papel institucional en la comarca y con sus potencialidades jurisdiccionales mermadas, la Corona no pudo evitar que esa pugna dejara su impronta en el paisaje. La obra comenzó a mostrar sus puntos débiles.

\subsection{Transformaciones paisajísticas}

La manifestación más visible de aquellas debilidades se produjo en la ribera del río. Existen datos dispersos que permiten vislumbrar un retroceso evidente en los logros conseguidos por la Real Obra y el deslinde de 1762 es solo uno de ellos. Gran parte de aquel quebranto vino de la mano de los molinos y se produjo en apenas veinte años. Se trata de informaciones indirectas, que hacen referencia a la necesidad de una nueva intervención y que forman parte del expediente relativo al pleito citado al comienzo de estas líneas. El proceso fue incoado a raíz de la denuncia que interpuso el fiscal de los Reales Desaguados, quien se hizo eco de la advertencia previa hecha por un tal Felipe Loaisa, "guarda notorio de los riates desaguados"36. En una de sus múltiples visitas a la vega, Loaisa se había percatado del aumento de la superficie encharcada en el tramo de río situado alrededor de Zuacorta, algo que relacionó con las obras que se habían hecho en el molino. Como consecuencia de aquellos reparos, se había "perdido la anivelación que debe guardar según lo dispuesto por superior orden"37. Dicho de otro modo: se había alterado el nivel máximo que debía tener su presa.

La maquinaria judicial no tardó en ponerse en marcha. Días después se llevó a cabo una nueva inspección. Aparte de confirmar la veracidad de los testimonios anteriores, el perito que se encargó de ella alertó del imparable crecimiento de la vegetación de ribera y sugirió que se interviniera en el río para devolver su aspecto al que casi medio siglo antes había resultado de la obra de desaguado. Según aquellas disposiciones, la madre del río debía tener una anchura mínima de entre quince y veinte varas (12,5 a 16,7 m.) en el tramo comprendido entre los Ojos y Muño Mocho y de entre 25 y 30 (20,8 a 25 metros) de ahí adelante (figura 1$)^{38}$. A juzgar por los testimonios recogidos en las semanas que siguieron a la denuncia, el Guadiana de finales del XVIII se parecía muy poco al que había resultado de la obra ejecutada a mediados de siglo. Por aquel entonces, el cauce había quedado definido y limpio y sus aguas totalmente corrientes. Atrás quedaban los años en los que el río había perdido su madre ${ }^{39}$ o en los que se hablaba de aguas contenidas y broza maciza (Celis et. al., 2017, p. 17). Gracias a aquella intervención se "aumentó el ueneficio en la desinundación de las riueras del rio" 40 porque "se explaya también a diferentes grandes porciones de tierra que han quedado desinundadas, que oy se cultiuan y rentan a fauor de la Real Hazienda" ${ }^{\prime 1}$.

El cambio en el paisaje del Guadiana era evidente. Pero no fue duradero. A finales de siglo la masiega "embarazaba" el río y amenazaba con inutilizar la maquinaria de algunos molinos ${ }^{42}$. Incluso, había zonas en las que la madre estaba "absolutamente" ciega ${ }^{43}$. La situación en el Cigüela no era mejor. El panorama que describen las Descripciones del cardenal Lorenzana, que fueron redactadas en los años ochenta del siglo XVIII, es muy clarividente: su "vega [era] pantanosa, llena de charcas [y] tan repleta de enea y carrizo, que todo parece un bosque de cañas" (Porres et al., 1985, p. 292).

Testimonios como los anteriores ponen en entredicho, no tanto el resultado de la desecación ejecutada a mediados de siglo, sino la política seguida con posterioridad. Para asegurar su perdurabilidad, la obra de los desaguados requería de una constante vigilancia y de la inversión en recursos económicos y humanos. De lo contrario, el agua y la vegetación avanzarían de forma inexorable. Y eso es lo que acabó por ocurrir. Además, debe contarse con el activo papel que jugaron las gentes del río, compleja maraña de individuos que, pese a estar unidos por el Guadiana, no siempre mantuvo una comunidad de intereses a la hora de servirse de él.

El cauce fue examinado en agosto de 1797 (tabla 4). A resultas de aquella inspección se constató la necesidad de intervenir urgentemente. Incluso se elaboró una suerte de plan de obra, que llegó a presupuestarse. Por desgracia, solo se poseen datos relativos al tramo de río comprendido entre los Ojos del Guadiana y el molino de Griñón (figura 1). Más allá de éste, comenzaba la dehesa de Zacatena. Privatizada aqueIla, tanto el juez conservador de los desaguados como los peritos que recorrieron el río manifestaron que aquella parte del río no era de su competencia. Por 
TABLA 4

PLAN DE ACTUACIÓN Y PRESUPUESTO DE LA OBRA DE DESBROCE DEL GUADIANA. AÑO 1797

\begin{tabular}{|c|c|c|c|c|c|c|c|c|}
\hline \multirow{4}{*}{\begin{tabular}{|l} 
tramo \\
Ojos-Batanejo
\end{tabular}} & \multirow{2}{*}{\multicolumn{2}{|c|}{ longitud (varas) }} & \multicolumn{2}{|c|}{$\begin{array}{l}\text { medidas intervención } \\
\text { requerida (en varas) }\end{array}$} & \multirow{4}{*}{$\begin{array}{l}\begin{array}{c}\text { varas } \\
\text { cúbicas }\end{array} \\
12000 \\
12000 \\
\end{array}$} & \multicolumn{3}{|c|}{$\begin{array}{l}\text { presupuesto } \\
\text { (en reales) }\end{array}$} \\
\hline & & & \multirow{3}{*}{$\begin{array}{c}\text { anchura } \\
16\end{array}$} & \multirow{3}{*}{$\begin{array}{c}\text { profundidad } \\
1\end{array}$} & & \multirow{3}{*}{$\begin{array}{c}\text { rls./vara }{ }^{3} \\
2 \\
0,5\end{array}$} & \multicolumn{2}{|c|}{ tasación final } \\
\hline & \multirow{2}{*}{15} & 750 & & & & & 24000 & 2000 \\
\hline & & 750 & & & & & 6000 & \\
\hline Batanejo-ruinas molino Arquel & \multicolumn{2}{|c|}{1025} & 16 & 1 & 16400 & 2 & & \\
\hline Ruinas molino Arquel-Zuacorta & \multicolumn{2}{|c|}{2600} & - & - & - & - & & $0^{(1)}$ \\
\hline Zuacorta-Parrilla (2) & \multicolumn{2}{|c|}{2000} & 6 & - & - & - & & \\
\hline Parrilla-Dehesa & \multicolumn{2}{|c|}{2000} & 13 & 1 & 26000 & 2 & & \\
\hline \multirow{2}{*}{ Dehesa- Nuevo de Curenga } & \multirow{2}{*}{2400} & $800^{(3)}$ & - & - & - & - & & \\
\hline & & 1600 & 16 & 1 & 25600 & 2 & & \\
\hline Nuevo de Curenga- Griñón ${ }^{(4)}$ & \multicolumn{2}{|c|}{-} & - & - & - & - & & \\
\hline
\end{tabular}

(1) Solo indica longitud y presupuesto final.

(2) Solo se indica la necesidad de abrir 6 varas de ancho.

(3) El tercio inicial del tramo se consideró acorde a lo establecido por Navacerrada.

(4) Zonas puntualmente afectadas. No se presupuestó ninguna intervención.

Fuente: AHN, OM, leg. 6433-2, fols. 18v-27r, 16.08.1797.

lo demás, se sabe que el costo de la limpieza debía ser sufragado por el propietario del molino situado al comienzo de cada tramo, criterio que se basaba en los usos tradicionales empleados en la ribera.

A juzgar por la tasación de las obras, el deterioro de la vega era manifiesto. La intervención era urgente, pero los trabajos quedaron interrumpidos y, que se sepa, no fueron retomados, al menos, hasta 1803. La metodología de las visitas que se hicieron entonces fue diferente y no se prestó tanta atención a la ribera como a los molinos. Ese cambio impide disponer de más datos acerca del estado de la madre del río, que, por fuerza, tuvo que empeorar. Sin embargo, ofrece información acerca del otro problema que amenazaba con echar por tierra el proyecto: las intervenciones irregulares que se habían producido en las presas de los molinos. Las inspecciones comenzaron en el de Doña Olalla y remontaron el río hasta llegar más allá de Zacatena. A raíz de ellas se constató que varios ingenios habían recrecido su presa. Algunos habían logrado el aval judicial a tales actuaciones, entre ellos el de El Emperador y el propio de Doña Olalla. En ambos se ejecutaron obras en torno a 1782. También hubo cambios en el Nuevo de Curenga: el nivel de su azuda se había elevado no menos de ocho pulgadas y un cuarto (unos $21 \mathrm{cms}$.). Aunque pueda parecer poco, en un escenario dominado por la escasa pendiente del río, ese recrecimiento suponía un verdadero problema ${ }^{44}$.

Poco más se sabe de aquella limpieza. Tan solo se poseen algunos datos sueltos que confirman que la operación no fue del agrado de todos y que, o bien no se ejecutó, o bien tuvo que repetirse en años sucesivos. Entre quienes mostraron reticencias estuvieron los propios freiles de San Juan. También la condesa de Montijo, "poseedora de la encomienda de Daimiel", quien mantuvo un constante tira y afloja con el juez de los desaguados a cuenta de esas tareas de desbroce. De hecho, se sabe que en 1806 se negó a cubrir los gastos generados por la limpieza del tramo de río que le correspondía ${ }^{45}$. Aparte de considerar que el proyecto era caro (lo valoró en sesenta mil reales), no estaba dispuesta a hacerse cargo del saneamiento aguas arriba de su molino, tarea que puede que se le encargara porque también era propietaria del molino de la Dehesa, en ruinas desde 1754 . Sea como fuere, el pleito de la condesa también es importante porque, aunque sea de manera indirecta, ofrece datos acerca de otras intervenciones en el río. En concreto da cuenta de un plan de limpieza que quiso ejecutarse en torno a 1780 y que, al parecer, tuvo que ser suspendido debido a las reticencias que despertó.

El mantenimiento de las lindes definidas por el apeo de 1754 también generó problemas. El crecimiento de la vegetación, la más o menos agresiva subida de las aguas ${ }^{46}$ y la actividad "depredadora" de linderos y ganados debieron someter a cierta presión a la obra. Así lo atestiguan, las referencias a las revisiones y reacondicionamientos que se ejecutaron en el propio amojonamiento y que afectaron a zonas en las que los intereses de los propietarios privados entraron en conflicto con los de la Real Hacienda. Uno de esos roces se dio en 1789 , cuando se tuvo que actuar en 
la ribera de Torralba de Calatrava ${ }^{47}$. Si bien es cierto que la intervención estuvo motivada por el deterioro de los mojones colocados a mediados de siglo, no es menos verdad que la revisión del apeo clarificó los límites entre propiedad privada y dominio público. La frase que el documento pone en boca del juez de los desaguados es muy clarificadora: "se evitan así entre sus vecinos [de Torralba] y los poseedores de los desaguados en lo futuro, las diferencias que hasta aquí se han experimentado".

No siempre fue posible evitar esos roces porque a las responsabilidades personales se unieron los intereses institucionales. Así ocurrió cuando los concejos de Carrión y Torralba se enfrentaron a cuenta de las quejas de uno de los arrendatarios de los desaguados, que había visto como sus pastos habían sido invadidos por los labradores de la primera villa. En realidad, el asunto no deja de ser un mero conflicto de competencias entre dos concejos, en el que cada uno defiende a sus vecinos. No obstante, lo realmente interesante es que aquella disputa intentaba dirimir si el rompimiento había sido en detrimento de los desaguados o si solo era competencia de la justicia ordinaria. Más allá de la importancia puntual de este hecho - que demuestra que la maquinaria administrativa erigida en 1753 funcionaba - el caso también es significativo porque informa de otra revisión del apeo, esta vez datada en $1792^{48}$.

Se trata de casos puntuales, posiblemente más frecuentes de lo que documentación deja ver, pero muy relevantes porque dan fe de un cambio de paradigma en la gestión del río. Hasta aquel momento, la conflictividad por el uso de sus recursos se había canalizado de manera más o menos eficaz a través de la guardería mayor de Zacatena. Sin embargo, a finales del siglo XVIII la dinámica institucional y socioeconómica de la comarca era muy diferente de la que había imperado durante toda la Edad Moderna: la obra de drenaje, el posterior amojonamiento y la entrada en escena del juez de los desaguados propiciaron un nuevo escenario en el que el paisaje y los recursos -el medio, en definitiva - eran un poco menos patrimonio común.

\section{CONCLUSIONES}

Entre los factores que se han puesto de relieve para explicar la intervención en la vega del Guadiana a mediados del siglo XVIII se ha prestado una atención especial a las motivaciones de tipo económico: la obra pretendió aumentar la superficie de cultivo y beneficiar a la oligarquía local terrateniente que demandaba más tierras de pasto. El plan de desecación resultaba acorde con esas exigencias en un contexto dominado por las ideas ilustradas y condicionado por las acuciantes necesidades financieras de la Corona española. De ahí el interés por ponerlo en marcha.

Lejos de quedar ahí, la obra patrocinada por el gobierno de Fernando VI tuvo otras ramificaciones que, hasta el momento, no habían sido analizadas y que no influyeron tanto en su realización, sino en el posterior devenir del Campo de Calatrava. Para dar satisfacción a los objetivos planteados, la obra del Guadiana debía contar con la previa reordenación de los recursos económicos de la comarca. La intervención en los molinos hidráulicos implicó la desaparición de algunos de ellos. Aunque aumentó la capacidad molturadora de los ingenios que se mantuvieron en pie, la merma era importante, máxime si se tiene en cuenta la coyuntura alcista del siglo. Ahí es donde se hace necesario mirar más allá del Guadiana, especialmente en dirección a otros cauces menores (Azuer, Jabalón, Bullaque...). El drenaje y desecación parcial del río solo pueden explicarse si se tiene en cuenta la presencia de molinos relativamente rentables en esos ríos, algo que, a juzgar por los datos que arroja el archivo, tuvo muy presente la Corona.

Por tanto, la desecación del Guadiana se enmarca en una política de intervención sobre los recursos naturales que trascendió al propio río y no solo en lo geográfico. En ese contexto también tuvo mucho que ver el plan de privatización de la Real Dehesa de Zacatena. Este trabajo ha demostrado la conexión entre ambas operaciones, incluso su simultaneidad temporal, hasta ahora intuida, pero no demostrada con referencias concretas. El problema es que, vendida la dehesa, las actuaciones desarrolladas hasta entonces comenzaron a ponerse en entredicho. Fue así porque, desde muy pronto, se hizo patente que la obra solo había resultado lucrativa para una parte de los habitantes de la comarca. La Corona también vio los límites de su operación: había ingresado el dinero por la venta de la dehesa - quien sabe si también de los desaguados-, pero no cejó en su empeño de seguir obteniendo provecho del río, especialmente a través de la vía impositiva.

Esa aspiración chocaba con el intento previo de beneficiar solo a los grupos rentistas. Aunque hubo conatos de mantener el nuevo statu quo generado por la desecación del río, lo cierto es que la obra experimentó un retroceso evidente en los años que siguieron a su culminación y en ello tuvieron mucho que ver los propietarios de los molinos, verdaderos damnificados hasta entonces. Finalizado el drenaje, fueron éstos 
quienes se apresuraron a aprovechar las carencias de un sistema jurisdiccional y regulatorio más fragmentado y débil, donde las instituciones de gestión del territorio creadas ex novo se mostraron menos eficaces que las que, hasta ese momento, habían ejercido en ese sentido. Por todo ello, cabe ver en la real obra de desaguado una suerte de proyecto cargado de buenas intenciones, pero totalmente fallido porque, en definitiva, solo permitió la privatización parcial de la ribera del río y de la dehesa de Zacatena, pero no cumplió su objetivo de hacer más rentable la vega, al menos de una forma sostenida en el tiempo y socialmente solidaria con las gentes del Guadiana.

\section{RECONOCIMIENTOS}

Trabajo apoyado por el proyecto de investigación Paisajes de tierra y agua. La conservación del medio natural en los aprovechamientos históricos de Las Tablas de Daimiel: la Dehesa de Zacatena y el río Guadiana, siglos XV-XIX (SBPLY/17/180501/000504), financiado por la Junta de Comunidades de Castilla-La Mancha y el Fondo Social Europeo.

El autor desea manifestar su profundo agradecimiento al profesor Francisco Fernández Izquierdo (CCHS-CSIC) por la cesión altruista de los datos relativos a 1762 contenidos en la tabla 3 así como por su generosa y desinteresada ayuda en la revisión del texto original.

\section{Biblografía}

Arroyo llera, F. (Intr.) (1993). Daimiel, 1752. Según las Respuestas Generales del Catastro de Ensenada. Madrid, España: Centro de Gestión Catastral y Cooperación Tributaria, Ministerio de Economía y Hacienda/Tabapress.

Arroyo llera, F. (2002). Orígenes y antecedentes de la Real Acequia del Jarama. Estudios Geográficos, 63 (248-249), 409-442. doi: https://doi.org/10.3989/ egeogr.2002.i248-249.233

Campos y Fernández de Sevilla, F. J. (2009). Los pueblos de Ciudad Real en las «Relaciones topográficas de Felipe I/». Ciudad Real, España: Diputación de Ciudad Real.

Celis Pozuelo, A. (2013). Las Tablas de Daimiel entre 1751 y 1887 . Las raíces históricas de su desecación. En II Jornadas de historia de Daimiel (pp. 277-291). Daimiel (Ciudad Real), España: Ayuntamiento.

Celis Pozuelo, A., Mediavilla López, R., Santiesteban Navarro, J. I., Castaño Castaño, S., y Losa Román,
A. de la. (2017). La desecación de las Tablas de Daimiel (1750-1987): Cambios agrarios e impactos medioambientales a partir de la interpretación del registro sedimentario. Historia Agraria, 71, 5-35.

Celis Pozuelo, A., Mediavilla López, R., Santiesteban Navarro, J. I., y Castaño Castaño, S. (2019). La Monarquía Hispánica y el control de los recursos hídricos. Hacia la desecación de Las Tablas de Daimiel de 1751. Hispania. Revista Española de Historia, 79 (261), 69-98. doi: https://doi.org/10.3989/ hispania.2019.003

Clemente Quijada, L. V. (2014). Las dehesas maestrales de La Serena (siglos XV-XVI): Cartografía de un paisaje social. Estudios Geográficos, 75 (277), 495-520. doi: https://doi.org/10.3989/estgeogr.201415

Corchado Soriano, M. (1972). Desamortización frustrada en el siglo XVIII. Cuadernos de estudios manchegos, 3, 87-107.

Corona Marzol, M. C. (1981). Las ordenanzas municipales de la villa de Castellón de la Plana en 1784. Pleitos entre agricultores y ganaderos a finales del siglo XVIII. Millars. Geografía-Historia, 7, 49-63.

Diago Hernando, M., y Ladero Quesada, M. Á. (2009). Caminos y ciudades en España de la Edad Media al siglo XVIII. En la España Medieval, 32, 347-382.

Doncel Fuentes, P., y Florín Beltrán, M. (2020). Anatomía Hidráulica de los Ojos del Guadiana (I). Ingeniería del agua, 24 (3), 169-181. doi: https://doi. org/10.4995/ia.2020.12387

Fernández Izquierdo, F. (2020). La dehesa de Zacatena en el siglo XVI: aproximación a sus ordenanzas y guardería mayor. En $V$ Jornadas de Historia de Daimiel. Daimiel (Ciudad Real), España: Ayuntamiento.

Fidalgo Hijano, C., y González Martín, J. A. (2013). El entorno de las Lagunas de Ruidera en el siglo XVIII a la luz del catastro de Ensenada y la cartografía de la época. Catastro, 77, 43-66.

Gil Olcina, A. (1992). Las políticas hidráulicas del reformismo ilustrado. En A. Gil Olcina y A. Morales Gil (Eds.), Hitos históricos de los regadíos españoles (pp. 143-182). Madrid, España: Ministerio de Agricultura, Alimentación y Medio Ambiente.

Hernández Benítez, M. (2002). El desembarco de los nuevos mesteños en Extremadura: La venta de la dehesa de La Serena y las transformaciones de la 
trashumancia, 1744-1770. Historia Agraria, 27, 65-100.

Hervás Herrera, M. Á. (2011). Molinos hidráulicos harineros de ribera en el Alto Guadiana. De los Ojos de Villarrubia a El Emperador. En P. Serrano de Menchén (Ed.), Tierra de cultura. I Curso de Historia de Argamasilla de Alba y Alto Guadiana (pp. 9-32). Argamasilla de Alba (Ciudad Real), España: Los Académicos de Argamasilla.

López Gómez, A. (2004). Las obras hidráulicas de Juan de Villanueva (1739-1811) y su adecuación geográfica. En Historia, clima y paisaje. Estudios geográficos en memoria del profesor Antonio López Gómez (pp. 429-438). Valencia, España: Publicacions de la Universitat de València, 2004.

López-Salazar Pérez, J. (1976). Evolución demográfica de la Mancha en el siglo XVIII. Hispania. Revista Española de Historia, 36 (133), 233-300.

López-Salazar Pérez, J. (1983). Un importante conflicto entre la Corona y los ganaderos mesteños: La medición del Valle de Alcudia de 1590. Estudios Geográficos, 44 (172), 395-434.

López-Salazar Pérez, J. (1987). Mesta, pastos y conflictos en el Campo de Calatrava durante el siglo XVI. Madrid, España: CSIC.

Marín Magaz, J. C. (2007). El hombre y el agua de las lagunas de Ruidera. Usos históricos, siglos XVI a mediados del XX. Tomelloso (Ciudad Real), España: Soubriet.

Marín Magaz, J. C., Fidalgo Hijano, C., y González Martín, J. A. (2008). Los padrones de riego de Argamasilla de Alba (Ciudad Real). Un documento paracatastral regulando los derechos al agua en los siglos XVIII y XIX. Catastro, 63, 181-202.

Mediavilla Martín, B. (2010). Inventario de documentos sobre el Monasterio de El Escorial existentes en el archivo de su Real Biblioteca. San Lorenzo, España: Ediciones Escurialenses.

Molas Ribalta, P. (1993). Los Fiscales de la Cámara de Castilla. Cuadernos de Historia Moderna, 14, 11-18.

Moleón Gavilanes, P. (1998). Juan de Villanueva. Madrid, España: Akal.

Moreno Díaz del Campo, F. J. (2005). Agua y harina. El molino de Flor de Ribera y la disputa por el control de los recursos del río Guadiana a principios del siglo XVIII en Torralba de Calatrava. En M. Romero y F. Alía (Eds.), Historia de Torralba de Calatrava.
Actas de las I y II Jornadas monográficas sobre Torralba de Calatrava y su entorno (2003-2004) (pp. 315-342). Torralba de Cva. (Ciudad Real), España: Ayuntamiento.

Moreno Díaz del Campo, F. J. (2009). Proyectos de abastecimiento hidráulico en el ámbito urbano durante el XVIII español: Ciudad Real y el arquitecto fray Marcos de Santa Rosa. En C. Fernández, V. M. Migués, y A. Presedo (Eds.), El mundo urbano en el siglo de la Ilustración. Vol. 1 (pp. 185-198). Santiago de Compostela, España: Xunta de Galicia.

Moreno Díaz del Campo, F. J. (2014). El aprovechamiento hidráulico del Guadiana: Los molinos de ribera. Siglos XV-XIX. En M. Mejías Moreno (Ed.), Las Tablas y los Ojos del Guadiana: Agua, paisaje y gente (pp. 147-184). Madrid, España: IGME-OAPN.

Moreno Díaz del Campo, F. J. (2015). ¿Agua para regar o agua para moler? La explotación del río Azuer durante la encomienda del II marqués de Velada en Manzanares (Ciudad Real) (1596-1616). Agua y territorio, 5, 86-98.

Moreno Díaz del Campo, F. J. (2017). Usos y representaciones del agua en la España árida: El río Jabalón durante el siglo XVIII. Revista de Humanidades, 32, 73-100. doi: https://doi.org/10.5944/ rdh.32.2017.18417

Porres de Mateo, J., Rodríguez de Gracia, H., Sánchez González, R. (Eds.) (1985). Los pueblos de la provincia de Ciudad Real a través de las descripciones del Cardenal Lorenzana. Toledo: Caja de Ahorros de Toledo.

Sánchez Marroyo, F. (2001). Un conflicto de intereses: Oligarcas y campesinos en la Real Dehesa de la Serena en los siglos XVIII y XIX. En E. la Parra López y M. Á. Melón Jiménez (Eds.), Manuel Godoy y la Ilustración (pp. 63-86). Mérida (Badajoz), España: Editora Regional de Extremadura.

Sánchez Sánchez, J. (2006). Caminos históricos Toledo-Córdoba por el Valle de Alcudia. En Caminería Hispánica. Actas del VII Congreso Internacional de Caminería Hispánica (pp. 1-25). Madrid, España: Ministerio de Fomento/Asociación Internacional de Caminería.

Santos Santos, J. F., y Moreno Díaz del Campo, F. J. (2009). Territorio, agua y sociedad. Hacia un modelo de distribución de los molinos hidráulicos en el entorno de las tablas de Daimiel. En Actas $V$ Congreso Internacional de Molinología (pp. 729740). Toledo, España: JCCM. 


\section{NOTAS}

1. Archivo Histórico Nacional, Sección Órdenes Militares (AHN, OM), leg. 6433-1, pieza 9, s.f., 26.12.1756.

2. La medición se hizo conforme a "la práctica y estilo de este Campo de Calatraua", empleando la cuerda (fanega) de 96 varas en cuadro (9216 varas cuadradas), que aproximadamente equivale a 0,6439 ha.

3. AHN, OM., leg. 6433-3, fols. 166r-168r, 23.11.1753.

4. AHN, OM, leg. 6433-3, fol. 167v, 23.11.1753.

5. Así lo prueba el hecho de que el molino de El Nuevo de Curenga, no fuera desalojado hasta mediados de diciembre. AHN, OM, leg. 5715.

6. Un quinto era la porción de terreno de la dehesa que podía proporcionar alimento a quinientas cabezas de ganado. Como indica López-Salazar, no tiene "nada que ver con el número de animales, sino con la superficie necesaria para alimentarse estos". Cf. López-Salazar, 1983, p. 397).

7. Archivo Histórico Provincial de Ciudad Real (AHP CR), Hacienda, leg. 685 (bienes de eclesiásticos), fols. 693r-694v.

8. AHN, OM, leg. 6433-3, fol. 403 y ss.

9. Se trata de un personaje con una extensa trayectoria al servicio de los primeros borbones. Fue caballero de Santiago y miembro de la Cámara de Castilla desde 1744. En lo que toca al tema aquí tratado, desempeñó el cargo de vocal de la Junta de Obras y Bosques en 1741 y durante los finales cuarenta y primeros cincuenta del Setecientos ejerció como juez privativo del Real Monasterio de El Escorial (Molas, 1993; Mediavilla, 2010). Respecto a su actuación en Zacatena, fue nombrado por Real Orden de 1 de septiembre de 1744 sustituyendo al cardenal Gaspar de Molina y Oviedo, gobernador del Consejo de Castilla (fallecido la víspera), que había sido nombrado inicialmente para la enajenación de las dehesas de la Serena y de la propia Zacatena. AHN, Consejos, leg. 51188-1. Debo esta la referencia al profesor Francisco Fernández Izquierdo, a quien agradezco su cesión.

10. Archivo Municipal de Torralba de Calatrava (AM Tor), caja 964, 19.6.1753.

11. AHP CR, Protocolos, leg. 610, fols. 283v-284r, 8.10.1762. La mojonera causó ciertos problemas entre el concejo y algunos vecinos. La escritura es un poder otorgado por el administrador de propios de la villa de Daimiel para que los apoderados pudiesen comparecer ante los tribunales

12. AHN, OM, Archivo de Toledo (AT), leg. 45973, fol. 90v.

13. AM Tor, $951,5.8 .1745$.

14. AHN, OM, leg. 6433-3, fols. 409r-415v, 15 y 16.9.1756.

15. AHM Torralba, caja 963, s.f.

16. AHN, OM, AT, leg. 46137, s.f.

17. AHN, OM, AT, leg. 47348, fols. 3r-v, 7.7.1717.

18. AHN, OM, AT, leg. 46566.

19. AHN, OM, AT, leg. 46574.

20. AHP CR, Protocolos, leg. 602-1, fols. 97r-v, 13.12.1718 y leg. 602-2, s. f., 23.12.1719.

21. AHP CR, Protocolos, leg. 602-1, fols. 101r-v, 18.12.1718 y leg. $602-2$, s.f., 27.05.1719

22. AHN, OM, leg. 5691-1.

23. AHN, OM, leg. 5691-2.

24. AHN, OM, AT, legs. 45973 y 45398.

25. AHN, OM, AT, legs. 47348 y 86780 . Lo cierto es que, por el desgaste al que estaban sometidos, los molinos eran objeto de reformas periódicas. Por ejemplo, Molemocho fue remozado en el siglo XVI. Por su parte, la encomienda de Daimiel actuó en 1678 en los tres molinos de los que era propietaria. AHN, OM, AT, leg. 38769 y 46272.

26. Un serio precedente fue el pleito que en 1716 enfrentó a los propietarios de El Nuevo de Curenga con el duque de Híjar. El pleito es conocido porque se hace referencia a él en otro posterior, de 1734 , en el que el duque se enfrentó con la villa de Daimiel. AHN, OM, AT, leg. 86717.

27. El caso de Zuacorta es significativo porque estaba alejado del epicentro del problema. El testimonio indica que antes de 1754 trabajaba "tasadamente" con una piedra en verano; después lo hizo tres y "con suficiente y abundante agua" $\mathrm{y}$ "tiene dicho molino en valor de rentta y bentta de tres partes las dos después de la obra". AHN, OM, leg. 6433-3, fol. 407r.

28. El testimonio del molinero es claro: antes de la obra solo funcionaban tres piedras (una en verano). Pasada la intervención eran seis y dos pilas de batán. AHN, OM, leg. 6433-3, fol. 388v. 
29. Ibidem, fol. 388r.

30. Ibidem, fol. $387 v$

31. Ibidem, fol. 396v-397r.

32. AHN, OM, leg. 6433-3, fol. 417v.

33. Solo se habían compensado ligeramente las pérdidas con la construcción del ya citado molino Nuevo de Malvecino, cuyas obras estaban concluidas en 1755. AHN, OM, leg. 6433-1, pieza 8, s.f., 15.8 .1755

34. En concreto, el hospital de la familia Caballería de Almagro y una capellanía administrada por Juan Antonio Ruiz en Almagro, que poseían un cuarto de La Parrilla cada uno y el convento de los dominicos de Almagro, que tenía la mitad de El Nuevo

35. Solo el molino de La Torre, perteneciente al señor de Malagón, estaba "desbaratado" y se desconoce si llegó a funcionar con posterioridad.

$36 \mathrm{AHN}, \mathrm{OM}$, leg. 6433-2 (Autos generales sobre la jurisdicción del prado hito en el molino de Zuacorta. 1797), fols. $2 r-3 r, 13.5 .1797$.

37. Ibidem, fol. 3v, 13.5.1797.

38. Ibidem.
39. AHN, OM, leg. 5691-1, s.f., 10.4.1726.

40. AHN, OM, leg. 6433-3, fol. 406r, 13.9.1756 (testimonio de Alfonso Hervás, vecino de Carrión, panadero).

41. Ibidem, fol. 403v-404r, 13.09.1756 (testimonio de Roque de Arenas, vecino de Carrión).

42. AHN, OM, leg. 6433-2, fols. 3r-v, 16.5.1797 (declaración de Antonio Gómez de Vera, perito, sobre el estado del molino Nuevo de Curenga).

43. Ibidem, fols. $18 \mathrm{v}-20 \mathrm{r}$.

44. Sobre este asunto, y retomando conceptos publicados en 2009 por Santos y Moreno, véase el análisis matemático de Doncel y Florín, 2020.

45. AHN, OM, AT, leg. 48660.

46. Se sabe, por ejemplo, que en el invierno de 1784 1785, la crecida del río arruinó parte del puente de Malvecino. Véase Porres et al., 1985, p. 137.

47. AM Tor, caja 952, 4.6.1789. La revisión del apeo se llevó a cabo en el paraje de Cenagosa.

48. AM Tor, caja 953, 8.8.1792. La orden de apeo fechada en 3.11.1792. En esta ocasión parece que el deslinde afectó no solo a los términos de Torralba y Carrión, sino también a los de la dehesa de Calatrava y Fernán Caballero (figura 1). 